UDC 614.72

DOI: 10.21668/health.risk/2020.4.09.eng

Research article

\title{
MARKERS SHOWING ALLERGIC REACTIONS IN CHILDREN CAUSED BY AEROGENIC EXPOSURE TO MANGANESE AND NICKEL COMPOUNDS
}

\author{
S.L. Valina ${ }^{1}$, I.E. Shtina ${ }^{1}$, O.A. Maklakova ${ }^{1,2}$, D.A. Eisfel'd ${ }^{1}$, O.Yu. Ustinova ${ }^{1,2}$ \\ ${ }^{1}$ Federal Scientific Center for Medical and Preventive Health Risk Management Technologies, \\ 82 Monastyrskaya Str., Perm, 614045, Russian Federation \\ ${ }^{2}$ Perm State University, 15 Bukireva Str., Perm, 614990, Russian Federation
}

\begin{abstract}
High prevalence of allergic diseases among children and their close relation with quality of the environment require new approaches to organizing diagnostic and prevention activities.

Our research objects were 247 children attending pre-school children facilities (PSCF).

It was detected that children who permanently lived and/or attended a pre-school facility for not less than three years under long-term chemical aerogenic exposure to manganese and nickel compounds in low doses (0.17-0.23 MPC average daily) had contents of these metals in their blood that were 1.9-2.0 times higher than the same parameter in children from the reference group and 1.7-2.1 times higher than background level in the region. Pre-school children with their biological media being contaminated with nickel and manganese compounds suffered from atopic dermatitis, allergic rhinitis, and bronchial asthma 1.3-4.5 times more frequently $\left(0.23 \leq R^{2} \leq 0.73 ; 59.2 \leq F \leq 388.1 ; p \leq 0.001\right)$.

Allergic diseases associated with aerogenic exposure to chemicals with sensitizing power have certain pathogenetic peculiarities such as active overall inflammatory reaction; sensitization in 54-86\% children (the parameter is $1.5-4.3$ times higher than in the reference group); cellular metabolism disorder; depletion of antioxidant protection resources in $72 \%$ children; deficient activity of phagocytic and humoral section in immunity (1.2 times lower than in the reference group); cytokine regulation disorders (2.4-2.5 time difference); reduced expression of a receptor that induces activation apoptosis; stronger sympathetic influence on heart rate modulation in $26.0 \%$ children. Basing on statistical analysis and model making, we determined markers that showed occurring allergic reactions caused by aerogenic exposure to manganese and nickel compounds. These markers are targets for prevention activities; they include growth in allergic pathologies prevalence; these pathologies occurring together with chronic inflammatory-proliferative diseases and disorders in the vegetative nervous system; increased contents of leukocytes, eosinophils, and immunoglobulin E specific to nickel in blood; a decrease in phagocyte number and contents of IgM, IgA in blood serum $\left(0.07 \leq R^{2} \leq 0.74 ; 19.3 \leq F \leq 713.2 ; p \leq 0.0001\right)$. markers.

Key words: allergic diseases, pre-school children, ambient air, chemicals with sensitizing power, manganese, nickel,
\end{abstract}

According to data obtained via multiple epidemiologic research both in Russia and abroad allergic diseases are among the most widely spread pathologies occurring in children [1-5]. It has been established that morbidity with certain allergic nosologies is 4.5 times higher among children living in large industrial centers where metallurgic and civil engineering enterprises and power industry are located and where traffic is intense than among children living on territories where sanitary-epidemiologic situation is relatively favorable. A leading factor that causes high prevalence of allergic pathologies among chil-

(C) Valina S.L., Shtina I.E., Maklakova O.A., Eisfel'd D.A., Ustinova O.Yu., 2020

Svetlana L. Valina - Candidate of Medical Sciences, Head of the Department for Children and Teenagers Hygiene (e-mail: valina@fcrisk.ru; tel.: +7 (342) 237-27-92; ORCID: https://orcid.org/0000-0003-1719-1598).

Irina E. Shtina - Candidate of Medical Sciences, Head of the Laboratory for Complex Issues of Children's Health with a Clinical Group dealing with Medical and Preventive Health Risk Management Technologies (e-mail: shtina_irina@mail.ru; tel.: +7 (342) 237-27-92; ORCID: http://orcid.org/0000-0002-5017-8232).

Olga A. Maklakova - Doctor of Medical Sciences, Head of the Consulting and Polyclinic Department; Associate professor at the Department for Human Ecology and Life Safety (e-mail: olga_mcl@fcrisk.ru; tel.: +7 (342) 236-80-98; ORCID: http://orcid.org/0000-0001-9574-9353).

Dar'ya A. Eisfel'd - Candidate of Biological Sciences, Deputy Director responsible for general issues (e-mail: eisfeld@fcrisk.ru; tel.: +7 (342) 236-77-06; ORCID: https://orcid.org/0000-0002-0442-9010).

Olga Yu. Ustinova - Doctor of Medical Sciences, Deputy Director responsible for clinical work; Professor at the Department for Human Ecology and Life Safety (e-mail: ustinova@fcrisk.ru; tel.: +7 (342) 236-32-64; ORCID: http://orcid.org/0000-0002-9916-5491). 
dren living in cities with developed industries is ambient air being contaminated with chemicals that have sensitizing properties (lead, manganese, nickel, and chromium) as well as negative reactions summating or mutually potentiating each other [6-11].

Results obtained via monitoring over ambient air quality in large industrial centers indicate that certain metals (manganese and nickel compounds) persist in ambient air in them in concentrations that either adhere to the fixed hygienic standards or exceed them [12-15].

Being predominantly haptens, inhaled chemicals with sensitizing properties oxidize due to metabolism and combine with proteins thus creating specific complex antigens; these antigens induce releasing local inflammation mediators and histamine liberation [16]. Initially negative environmental factors act as triggers or primers that stimulate pathogenic processes in critical organs and systems together with destabilization in adaptation processes and damage done to resistance mechanisms [17-20].

It is necessary to develop new approaches to spotting out target population groups and determining relevant medical and preventive activities taking into account adverse effects occurring when biological media are contaminated with technogenic chemicals that have sensitizing properties. It will allow preventing high growth rates detected for morbidity with allergic diseases.

Our research goal was to determine markers that indicated allergic reactions occurrence in children associated with aerogenic exposure to nickel and manganese compounds.

Data and methods. Our test group included 107 children aged 5-7 who permanently lived and/or attended a pre-school children facility (PCF) on a territory where nickel and manganese compounds were contained in ambient air in concentrations equal to $0.17-0.23$ average daily MPC. Our reference group was made up of 240 children attending a PCF who were not exposed to chemicals with sensitizing properties contained in ambient air. Both groups were comparable in terms of age and $\operatorname{sex}(p>0.05)$.

Medical examinations were performed in conformity with the ethical principles stated in Helsinki Declaration (1964; last edited in October 2013). Prior to any examinations, parents or legal representatives gave their informed voluntary consent on medical intervention and personal data processing.

Nickel and manganese compounds contents were quantitatively determined in children's blood as per methodical guidelines 4.1.3230-14 ${ }^{1}$.

Medical and sociological data were obtained via questioning with parents participating in it.

Morbidity was analyzed as per data taken from medical documentation (Form No. 026/u-2000) and results obtained via medical examinations (performed by allergologists, otorhinolaryngologists, pediatricians, and neurologists).

Laboratory diagnostics included examining integral hematologic parameters, immunologic and metabolic status, non-specific resistance, sensitization, and oxidation-antioxidant processes.

Vegetative regulation was assessed via analyzing heart rate modulation performed with «Poly-Spectr-8/EX» program (Neurosoft, Ruissia).

Data were analyzed with Statistica 6.0 software package and specific software products that were compatible with MS-Office. We applied two-sample Student's t-test to compare both groups as per quantitative parameters. Dependence between parameters was assessed via one-factor dispersion analysis and correlation-regression analysis. To quantitatively determine closeness of correlations between parameters, we calculated odds ratio (OR) and its confidence interval (CI). Discrepancies between obtained results were considered statistically significant at $p \leq 0.05$.

Results and discussion. We performed chemical and analytical examination of ambi-

\footnotetext{
${ }^{1}$ MG 4.1.3230-14. Measuring mass concentrations of chemical elements in biological media (blood and urine) with mass spectroscopy with inductively coupled plasma. KODEKS: an electronic fund for legal and reference documentation. Available at: http://docs.cntd.ru/document/495856222 (12.09.2020) (in Russian).
} 
ent air quality on territories where PCF were located (2014-2018); it revealed that nickel and manganese compounds persisted in ambient air on the test territory in quantities equal to $0.17-0.23$ average daily MPC. Average nickel and manganese compounds contents amounted to $0.00014 \pm 0.000029 \mathrm{mg} / \mathrm{m}^{3}$ and $0.00019 \pm 0.00004 \mathrm{mg} / \mathrm{m}^{3}$ and it was higher than the same parameters on the reference territory $\left(0.000012 \pm 0.000002 \mathrm{mg} / \mathrm{m}^{3}\right.$ and $\left.0.000025 \pm 0.000005 \mathrm{mg} / \mathrm{m}^{3}, p \leq 0.0001\right)$.

Having analyzed technogenic chemicals contents in children's blood, we established that nickel and manganese compounds contents were 1.9-2.0 times higher in blood of children from the test group than in blood of those from the reference one $(0.0047 \pm 0.0013$ against $\quad 0.0025 \pm 0.0006 \quad \mu \mathrm{g} / \mathrm{cm}^{3} \quad$ and $0.022 \pm 0.012$ against $0.011 \pm 0.001 \mu \mathrm{g} / \mathrm{cm}^{3}$ accordingly, $p \leq 0.0001$ ) and 1.7-2.1 times higher than the regional background level $(p \leq 0.001)$. A share of blood samples with elevated nickel and manganese compounds contents was 2.5-2.6 times higher in the test group than in the reference one (72.7 \% against $28.8 \%$ and $57.1 \%$ against $22.1 \%, p \leq 0.0001-0.001 ; 4.6 \leq \mathrm{OR} \leq 6.44$; $2.53 \leq \mathrm{CI} \leq 12.2 ; 0.0001 \leq p \leq 0.001)$.

Sociologic research didn't reveal any statistically significant discrepancies between the analyzed groups as per social, medical-biological $(p>0.05)$ and other factors (including peculiarities related to surrounding plants and periods when they give pollen) that were able to cause similar health disorders in children.

We comparatively analyzed data taken from medical documentation (Form No. 026/u) and data obtained via medical examinations; the analysis revealed that pre-school children with high sensitizing chemicals contents in blood suffered from atopic dermatitis (L20.8, L20.9) 1.3 times more frequently (48.6 and $36,7 \%, p=0.04)$; allergic rhinitis (J30.3, J30.4), 1.4 times more frequently (25.0 and $18.4 \%, p=0.04$ ); bronchial asthma (J45), 4.5 times more frequently $(9.0$ and $2.0 \%$, $p=0.003$ ) than children from the reference group. A share of children with combined respiratory and skin allergies was 1.5 times higher among children from the test group (47.0 against $32.0 \%, p=0.007)$. We established an authentic correlation between higher morbidity among children with predominantly allergic asthma (J45.0), mixed asthma (J45.8), and atopic dermatitis (L20.8, L20.9) and increased manganese concentration in blood $\left(0.23 \leq R^{2} \leq 0.52\right.$; $59.2 \leq F \leq 279.5 ; p \leq 0.001)$. A contribution made by nickel into predominantly allergic asthma (J45.0), allergy, unspecified (T78.4), and atopic dermatitis (L20.8, L20.9) can amount to $37.0-73.0 \%(130.6 \leq F \leq 388.1$; $p \leq 0.001)$.

Respiratory diseases and certain immune disorders occurred accordingly in $94.0 \%$ and $67.0 \%$ children from the test group and it was 1.6 times more frequent than among children from the reference group $(57.1 \%$ and $41.0 \%$ accordingly, $p \leq 0.001)$. We established that aerogenic exposure to nickel and manganese compounds resulted in 2.9-11.0 times more frequent occurrence of diseases from these nosologic groups (ICD-10) $(\mathrm{OR}=2.9-11.0$; $\mathrm{CI}=1.64-29.50 ; p \leq 0.0001)$. We comparatively analyzed frequency of specific respiratory nosologies and revealed that children from the test group suffered from chronic diseases of tonsils and adenoids (J35.0, J35.1, J35.2, J35.3, J35.8, J35.9) 3.0 times more frequently than children from the reference group (42.0 against $14.0 \%, p \leq 0.0001$ ). We established dependence between chronic diseases of tonsils and adenoids and nickel and manganese compounds contents in blood $\left(0.18 \leq R^{2} \leq 0.73\right.$; $45.03 \leq F \leq 713.2 ; p \leq 0.0001)$. As for diseases of the nervous system, the most significant discrepancies between the examined groups were revealed for «Disorder of autonomous nervous system, unspecified» nosology (G90.9) as it was diagnosed in $19.0 \%$ children from the test group and only $10.0 \%$ children from the reference one $(p=0.02)$. A contribution made by nickel into autonomous nervous system disorders amounted to $44.0 \%$; by manganese, $74.0 \%(F=214.3-757.9$; $p \leq 0.0001)$. 
We assessed changes in hematologic parameters and overall inflammation reactions in a body; the assessment revealed authentic discrepancies between contents of leukocytes $\left(7.50 \pm 0.33 \cdot 10^{9} / \mathrm{dm}^{3}\right)$, monocytes $(7.75 \pm 0.34 \%)$, and thrombocytes $\left(326.68 \pm 11.98 \cdot 10^{9} / \mathrm{dm}^{3}\right)$ in children from the test group and physiological standards $(p<0.001)$ as well as the same parameters in children from the reference group $\left(7.07 \pm 0.26 \cdot 10^{9} / \mathrm{dm}^{3}\right.$, $7.02 \pm 0.24 \%, 293.62 \pm 9.60 \cdot 10^{9} / \mathrm{dm}^{3}$ accordingly, $p=0.000-0.05)$. A share of blood samples with elevated monocytes, leukocytes, and thrombocytes contents amounted to $89.7 \%$, $90.7 \%$, and $48.6 \%$ accordingly in the test group and it was 1.2-1.6 times higher than the same parameters in the reference group (73.8 \%, $45 \%, 30.6 \%, p=0.001-0.007)$. We established a direct correlation between concentrations of nickel and its compounds in blood and monocytosis $(r=0.12, p=0.04)$. There was also an authentic correlation between a probable increase in leukocytes contents in blood and elevated manganese concentration in blood with its contribution being equal to $26 \%(F=97.2 ; p \leq 0.0001)$.

Children with their biological media being contaminated with metals had elevated relative eosinophils contents in blood $(4.38 \pm 0.58 \%)$ and their eosinophilic-lymphocytic index was also higher $(0.108 \pm 0.016$ arb. units $)$ than the physiological standard $(p<0.0001)$ and the same parameters in the reference group $(3.17 \pm 0.36 \%$ and $0.07 \pm 0.01$ arb. units accordingly, $p \leq 0.001)$. It indicated that specific regain cellular forms participated in inflammation. Primering effects produced by these chemicals on hyper-reactivity occurrence are confirmed by established dependence between eosinophilia intensity and manganese $\left(R^{2}=0.25 ; F=93.2 ; p \leq 0.0001\right)$ and nickel $\left(R^{2}=0.32 ; F=126.9 ; p \leq 0.0001\right)$ concentrations in blood.

Alkaline phosphatase tended to be less active in children from the test group $\left(342.88 \pm 12.41\right.$ against $366.84 \pm 10.26 \mathrm{U} / \mathrm{dm}^{3}$, $p \leq 0.001)$ and it was probably due to membrane-toxic effects produced by manganese and active metabolic consumption occurring during biotransformation. Protein-forming functions performed by the liver were reduced in children with elevated chemicals with sensitizing properties in blood as it was indicated by lower overall protein $\left(70.96 \pm 0.89 \mathrm{~g} / \mathrm{dm}^{3}\right)$ and albumins $\left(42.40 \pm 0.93 \mathrm{~g} / \mathrm{dm}^{3}\right)$ contents in blood serum against the same parameters in the reference group $\left(72.54 \pm 0.59 \mathrm{~g} / \mathrm{dm}^{3}\right.$ and $\left.43.6 \pm 0.59 \mathrm{~g} / \mathrm{dm}^{3}, p=0.01-0.03\right)$. We revealed an inverse correlation between nickel concentration and albumins contents in blood $(r=-0.162, p=0.008)$.

Antioxidant protection was depleted and it became apparent via lower plasma antioxidant activity (AOA) in $72 \%$ children from the test group and it was 1.3 times higher than the same parameter in the reference group (53\%, $p=0.001)$. Average group AOA value was lower for children living under aerogenic exposure to manganese and nickel compounds than for children from the reference group $(34.002 \pm 1.09$ against $35.911 \pm 0.66 \%$, $p \leq 0.001)$ and lower than the bottom limit of the physiological standard $(p<0.0001)$. Antioxidant reserves depletion was 2.3 times more probable among children from the test group than among those from the reference one $(\mathrm{OR}=2.26, \mathrm{CI}=1.27-4.10 ; p=0.009)$.

Th-1-dependent response tended to be inhibited in children with their biological media being contaminated with metals; it was characterized with a decrease in gammainterferon as the most significant atopic processes regulator; its level was 2.4 times lower among children from the test group than in those from the reference one $(3.26 \pm 2.91$ against $7.84 \pm 3.25 \mathrm{pg} / \mathrm{mL}, p=0.03)$.

Average VEGF protein contents was 2.5 times higher in children from the test group than in those from the reference one $(172.88 \pm 51.47$ and $67.95 \pm 20.10 \mathrm{pg} / \mathrm{mL}$, $p<0.0001)$; this protein promotes allergic inflammation due to its ability to increase vascular permeability.

Despite there were no discrepancies in quantitative parameters showing overall immunoglobulin E (IgE) production in children from the examined groups $(101.51 \pm 35.12$ and $78.84 \pm 31.09 \mathrm{IU} / \mathrm{mL}, p=0.25)$, elevated spe- 
cific IgE levels were more frequently revealed in pre-school children from the test group as $53.6 \%$ children had IgE specific to cat fur with its value being higher than the physiological standard (it was 2.3 times higher than the same parameter in the reference group, $23.1 \%, p<0.0001 ; \mathrm{OR}=3.08, \mathrm{CI}=2.09-7.07$; $p<0.0001) ; 85.7 \%$ children had IgE specific to Aspergillusniger (1.4 times higher than in the reference group, $p<0.0001 ; \mathrm{OR}=3.9$, $\mathrm{CI}=2.01-7.95 ; p<0.0001)$. Average group values of IgE specific to Dermatophagoides pteronissimus and to Aspergillus niger were also authentically 2.5-4.3 times higher among exposed children than among those from the reference group $(0.4 \pm 0.14$ against $0.16 \pm 0.06$ a.u. and $0.26 \pm 0.09$ against $0.06 \pm 0.03$ a.u., $p<0.0001)$. These detected peculiarities are related to technogenic chemical factors initially acting as primers and inducing sensitization. Immunoglobulin E specific to nickel was authentically 1.5 times higher in pre-school children from the test group than the same parameter in children from the reference one $\left(0.28 \pm 0.05\right.$ against $0.18 \pm 0.02 \mathrm{IU} / \mathrm{cm}^{3}$, $p<0.0001)$. We detected a statistically authentic cause-and-effect relation between IgE specific to nickel and nickel contents in blood $\left(R^{2}=0.49 ; F=71.13 ; p \leq 0.0001\right)$.

Children with their biological media being contaminated with manganese and nickel compounds tended to have hypofunction of the humoral section in the immunity as $64.2-72.5 \%$ of them had lower immunoglobulin $\mathrm{M}\left(1.21 \pm 0.04 \mathrm{~g} / \mathrm{dm}^{3}\right)$ and $\mathrm{G}$ $\left(10.16 \pm 0.29 \mathrm{~g} / \mathrm{dm}^{3}\right)$ contents in their blood serum than the physiological standard $(p<0.0001)$. IgM contents was 1.2 times lower among them than in children from the reference group $\left(1.21 \pm 0.04 \mathrm{~g} / \mathrm{dm}^{3}\right.$ and $1.4 \pm 0.06 \mathrm{~g} / \mathrm{dm}^{3}, p<0.0001$ ), and a decrease in IgM contents was 4.0 times more probable in the test group $(\mathrm{OR}=4.01, \mathrm{CI}=2.25-7.34$; $p=0.00)$. We established an inverse correlation between nickel contents in blood and IgM concentration $(r=-0.133, p=0.03)$. We also established that children from the test group had lower IgA contents in their blood serum than their counterparts from the reference group $\left(1.39 \pm 0.07\right.$ against $1.49 \pm 0.11 \mathrm{~g} / \mathrm{dm}^{3}$, $p<0.0001)$ and it was due to effects procured by nickel $\left(R^{2}=0.35 ; F=144.75 ; p<0.001\right)$.

We analyzed non-specific resistance as per overall phagocytosis parameters and revealed that pre-school children from the test group had up to 1.2 times lower phagocytic index $(1.82 \pm 0.04$ a.u.) and phagocytic number $(0.88 \pm 0.06$ a.u. $)$ than children from the reference group $(2.06 \pm 0.09$ and $1.05 \pm 0.11$ a.u. accordingly, $p \leq 0.001-0.01) .49 .5 \%$ children from the test group had lower phagocytic number and it was 1.6 times higher than the same parameter in the reference group $(30.6 \%$, $p=0.001)$. A decrease in phagocytic number was 2.2 times more probable in children from the test group than in those from the reference one $(\mathrm{OR}=2.2, \mathrm{CI}=1.25-3.96 ; p=0.01)$. We established an authentic decrease in phagocytic number in case manganese contents in blood were elevated $\left(R^{2}=0.07 ; \quad F=19.3\right.$; $p=0.0001)$.

$65.0 \%$ children who had sensitizing chemicals in their blood in quantities up to 2.1 times higher than the regional background level had lower expression of activation apoptosis induction receptor among CD95 + lymphocytes against the reference group $(14.65 \pm 2.45$ against $23.95 \pm 3.52 \%$ and $0.43 \pm 0.08 \cdot 10^{9} / \mathrm{L}$ against $\left.0.68 \pm 0.14 \cdot 10^{9} / \mathrm{L}, \quad p \leq 0.001-0.002\right)$. A decrease in relative CD3+CD95+-lymphocytes contents was 7.2 times more probable and a decrease in their absolute quantity was up to 17.0 times more probable in children from the test group than in those from the reference one $\quad(7.25 \leq \mathrm{OR} \leq 17.36 ; \quad 3.92 \leq \mathrm{CI} \leq 50.68$; $p<0.0001)$.

Non-specific mechanisms play a significant role in allergic reactions occurrence; in particular, we can mention imbalance between sympathetic and parasympathetic sections in the nervous system. Greater sympathetic influence on heart rate modulation was detected in each forth child from the test group $(25.7 \%)$ and it was 2.3 times more frequent than in the reference one $(11.0 \%$, $p=0.03)$. Sympathetic regulation prevalence was 2.7 times more probable among preschool children from the test group than 
among those from the reference one $(\mathrm{OR}=2.7$; $\mathrm{CI}=1.3-6.05 ; p=0.01$ ).

We performed statistical analysis of data obtained via sanitary-hygienic, clinical-laboratory, and functional examinations; assessed dependence between parameters; built and analyzed relevant models. All this allowed us to establish markers and peculiarities of pathogenetic mechanisms responsible for negative effects occurrence such as allergic reactions in pre-school children living under long-term aerogenic exposure to chemicals contained in ambient air in low doses.

Key pathogenetic sections in allergic diseases occurrence under aerogenic exposure to technogenic chemicals with sensitizing properties (manganese and nickel compounds) include the following: a decrease in proteinforming function performed by the liver ( $\downarrow$ albumins; $r=-0.162, p=0.008)$, inhibited humoral section in the immune response $\left(\downarrow \operatorname{IgM}, \operatorname{IgA} ; R^{2}=0.35 ; F=144.75 ; p<0.001\right.$; $r=-0.133, p=0.03)$, and specific sensitization ( $\uparrow \operatorname{IgE}$ specific to nickel; $R^{2}=0.49$; $F=71.13 ; \quad p \leq 0.0001)$ for nickel; lower phagocytic activity ( $\downarrow$ phagocytic number compounds; $R^{2}=0.07 ; F=19.3 ; p=0.0001$ ) for manganese; there are also sections related to nickel and manganese compounds contents in blood such as non-specific sensitization ( $\uparrow$ eosinophils; $\quad 0.25 \leq R^{2} \leq 0.32 ; \quad 93.2 \leq F \leq$ $\leq 126.9 ; p \leq 0.0001)$, overall inflammation reaction activity ( $\uparrow$ monocytes and leukocytes; $r=0.12, p=0.04 ; R^{2}=0.26 ; F=97.2$; $p \leq 0.0001)$.

Therefore, allergic reactions associated with aerogenic exposure to nickel and manganese compounds have the following markers: a 1.5 times increase in prevalence of combined allergic pathologies; comorbidity with chronic inflammatory-proliferative diseases (up to 3.0 times higher), disorders of the autonomous nervous system (up to 1.9 times higher); apparent non-specific (leukocytosis is 1.1 times higher) and immune (monocytosis is 1.3 times higher) inflammation; inhibited humoral section (IgM and $\operatorname{IgA})$ and 1.2 times lower phagocytic activity (phagocytic number); specific sensitization (1.5 times higher IgE specific to nickel); non-specific sensitization (1.5 times higher eosinophilia); depleted antioxidant protection (1.1 times lower AOA).

Established markers are target ones for diagnostic and preventive activities. Basic preventive activities aimed at reducing or eliminating allergic reactions caused by aerogenic exposure to chemicals with sensitizing properties should include the following: a decrease in chemicals contents in a body; sanitation of chronic infection foci such as ENT organs; reduction in inflammation processes activity; recovery of antioxidant protection and vegetative homeostasis; immune response modulation.

\section{Conclusions:}

1. Atopic dermatitis, allergic rhinitis, and bronchial asthma were diagnosed 1.3-4.5 times more frequently among children from the test group than among children from the reference group $\left(0.23 \leq R^{2} \leq 0.73\right.$; $59.2 \leq F \leq 388.1 ; p \leq 0.001)$ since children from the former group lived under long-term aerogenic exposure to nickel and manganese compounds in low doses $(0.17-0.23$ average daily MPC) and had these compounds in their blood in contents 1.7-2.1 times higher than the regional background level.

2. Pre-school children with elevated nickel and manganese compounds in their blood had certain pathogenetic peculiarities detected in their bodies regarding allergic diseases such as overall inflammatory reaction activity (60.7-89.7\% children); sensitization (53.6-85.7\% children); depleted antioxidant reserves $(72.0 \%$ children $)$; cellular metabolism disorders and disorders of the humoral and phagocytic sections in the immunity (49.5-72.5\% children); apoptosis regulation disorders $(65.0 \%)$; intra-cellular interaction disorders and vegetative imbalance $(25.7 \%$ children).

3 . We established markers of allergic reactions associated with aerogenic exposure to chemicals with sensitizing properties (nickel and manganese compounds) that were target ones for preventive activities. They included humoral section (IgM, IgA) inhibition and spe- 
cific sensitization (IgA specific to nickel) caused by effects produced by nickel $\left(0.35 \leq R^{2} \leq 0.49\right.$; $71.13 \leq F \leq 144.75 ; p \leq 0.001)$; lower phagocytic activity (phagocytic number) caused by exposure to manganese $\left(R^{2}=0.07 ; F=19.3\right.$; $p=0.0001$ ); non-specific sensitization (eosinophils) and inflammation (leukocytes) caused by exposure to nickel and manganese $\left(0.25 \leq R^{2} \leq 0.32 ; 93.2 \leq F \leq 126.9 ; p \leq 0.0001\right)$.

Funding. The research was not granted any sponsor support.

Conflict of interests. The authors declare there is no any conflict of interests.

\section{References}

1. Balabolkin I.I., Terletskaya R.N. Allergic case rate of children and adolescents in the modern ecological conditions. Pediatr, 2014, vol. 5, no. 2, pp. 40-46 (in Russian).

2. Burlutskaya A.V., Firsova V.N., Sutovskaya D.V., Tralenko E.S., Dremlyugova A.F. Antiinflammatory antileukotrienes efficiency (almont as an example) to control bronchial asthma and allergic rhinitis in children. Mezhdunarodnyi nauchno-issledovatel'skii zhurnal, 2017, vol. 55, no. 1-1, pp. 90-97 (in Russian).

3. Gurtovaya M.N., Prokop'ev N.Ya., Kolunin E.T., Gubin D.G., Durov A.M. Allergic rhinitis and bronchial asthma: the incidence, causes, and treatment (review of foreign literature). Mezhdunarodnyi zhurnal prikladnykh i fundamental'nykh issledovanii, 2016, vol. 10, no. 1, pp. 29-37 (in Russian).

4. Shvetsova E.S., Korotkova T.S. The prevalence of allergic diseases among all age groups of the population of Lipetsk region. Sovremennye problemy nauki i obrazovaniya, 2017, no. 4, pp. 92-93 (in Russian).

5. Ballardini N., Kull I., Lind T., Hallner E., Almqvist C., Ostblom E., Melén E., Pershagen G. [et al.]. Development and comorbidity of eczema, asthma and rhinitis to age 12: data from the BAMSE birth cohort. Allergy, 2012, vol. 67, no. 4, pp. 537-544. DOI: 10.1111/j.1398-9995.2012.02786.x

6. Oh I., Lee J., Ahn K., Kim J., Kim Y.-M., Sim C.S., Kim Y. Association between particulate matter concentration and symptoms of atopic dermatitis in children living in an industrial urban area of South Korea. Environ Res, 2018, no. 160, pp. 462-468. DOI: 10.1016/j.envres.2017.10.030

7. Shima M. Health Effects of Air Pollution: A Historical Review and Present Status. Nihon Eiseigaku Zasshi, 2017, vol. 72, no. 3, pp. 159-165. DOI: 10.1265/jjh.72.159

8. Nesterova A.V., Potaturkina-Nesterova N.I., Nesterov A.S. The current state of the problem of allergic rhinitis in children. Sovremennye problem nauki i obrazovaniya, 2015, no. 5, pp. 226-227 (in Russian).

9. Sineva E.L., Pankova V.B., Sarancha E.O. The prevalence and structure of ENT diseases in the children residing in the industrial regions. Vestnik otorinolaringologii, 2015, vol. 80, no. 2, pp. 48-52 (in Russian).

10. Ernazarova Kh.Kh., Adylova Z.U. The prevalence of allergic diseases in the world. International scientific review, 2017, vol. 33, no. 2, pp. 48-52 (in Russian).

11. Paciencia I., Rufo J.C., Silva D., Martins C., Mendes F., Rama T., Rodolfo A., Madureira J. [et al.]. School environment associates with lung function and autonomic nervous system activity in children: a cross-sectional study. Scientific Reports, 2019, no. 9, pp. 15156. DOI: 10.1038/s41598-019-51659-y

12. Kleyn S.V., Vekovshinina S.A., Balashov S.Yu., Kamaltdinov M.R., Atiskova N.G., Nedoshitova A.V., Khankhareev S.S., Madeeva E.V. Analysis of cause-effect relations of the levels of biological markers of exposure to heavy metals with their personalized loading dose in the areas of wastes' influence induced by the operation of the metallurgical plant in the past. Gigiena i sanitariya, 2017, vol. 96, no. 1, pp. 29-35 (in Russian).

13. Dolgikh O.V., Krivtsov A.V., Bubnova O.A., Otavina E.A., Bezruchenko N.V., Kolegova A.A., Mazunina A.A., Gusel'nikov M.A. Features of fixing the genetic polymorphism in dyads «motherchild» in the conditions of aerogenous exposure to metals. Gigiena i sanitariya, 2017, vol. 96, no. 1, pp. 26-29 (in Russian).

14. Arruti A., Fernández-Olmo I., Irabien A. Impact of the global economic crisis on metal levels in particulate matter (PM) at an urban area in the Cantabria Region (Northern Spain). Environ Pollut, 2011, vol. 159, no. 5, pp. 1129-1135. DOI: 10.1016/j.envpol.2011.02.008 
15. Zanoletti A., Bilo F., Borgese L., Depero L.E., Fahimi A., Ponti J., Valsesia A., La Spina R., Montini T., Bontempi E. SUNSPACE, A Porous Material to Reduce Air Particulate Matter (PM). Front Chem, 2018, no. 6, pp. 534. DOI: 10.3389/fchem.2018.00534

16. Zaitseva N.V., Ustinova O.Yu., Sboev A.S. Medical and preventive technologies for risk management of health problems associated with exposure to environmental factors. Gigiena $i$ sanitariya, 2016, vol. 95, no. 1, pp. 17-22 (in Russian).

17. Maklakova O.A., Ustinova O.Yu., Alekseeva A.V. Age structure and dynamics of the morbidity rate of respiratory and autonomous nervous system diseases in children living in conditions of the aerogenous impact of chemical factors of technogenic origin (cohort study). Gigiena i sanitariya, 2017, vol. 96, no. 1, pp. 75-78 (in Russian).

18. Simonova I.N., Antonyuk M.V. Role of industrial air pollution in growth of bronchopulmonary pathology. Zdorov'e. Meditsinskaya ekologiya. Nauka, 2015, vol. 59, no. 1, pp. 14-20 (in Russian).

19. Khismatullina Z.N. Zabolevaniya, svyazannye s vozdeistviem khimicheskikh faktorov okruzhayushchei sredy [Diseases caused by exposure to chemical environmental factors]. Vestnik Kazanskogo tekhnologicheskogo universiteta, 2013, vol. 16, no. 20, pp. 170-178 (in Russian).

20. Silvestre M.C., Dos Reis V.M.S. Evaluation of the profile of inflammatory cytokines, through immunohistochemistry, in the skin of patients with allergic contact dermatitis to nickel in the acute and chronic phases. An Bras Dermatol, 2018, vol. 93, no. 6, pp. 829-835. DOI: 10.1590/abd1806-4841.20187126

Valina S.L., Shtina I.E., Maklakova O.A., Eisfel'd D.A., Ustinova O.Yu. Markers showing allergic reactions in children caused by aerogenic exposure to manganese and nickel compounds. Health Risk Analysis, 2020, no. 4, pp. 85-92. DOI: 10.21668/health.risk/2020.4.09.eng

Received: 29.09 .2020

Accepted: 21.11 .2020

Published: 31.12.2020 